\title{
KONSEP KETUHANAN ISLAM JAWA DIENG \\ (Studi Terhadap Aliran Tunggul Sabda Amungraga)
}

\author{
Bani Sudardi \\ Universitas Sebelas Maret, Surakarta \\ Jl. Ir. Sutami 36A Kentingan Solo. Telp (0271) 632450 \\ E-mail: soedardibanie@gmail.com \\ HP. +62-81329111466
}

Abstract: This research reveals the teaching of a religious sect in Dieng which focuses on theological concept. Clifford Geerts' concept is used to discuss the social and art area. There are some results on this research; a belief to the invisible nature, the Islamic teaching from Sunan Kalijaga, Mataram teaching with some enculturation, and a statement that Allah is the only one who is worth to be worshipped.

Abstrak: Penelitian ini mengungkap tetang ajaran pada aliran kepercayaan di Dieng dengan konsep ketuhanan sebagai titik perhatian utama. Dalam penelitian ini, digunakan cara berpikir dari Clifford Geertz untuk memasuki ranah sosial budaya, yang kemudian ditafsirkan oleh peneliti dengan data yang ditemukan di lapangan. Hasil yang ditemukan adalah adanya kepercayaan pada alam gaib dengan asal manusia dari Adam dan Hawa, ajaran yang bersumber dari Sunan Kalijaga dan ajaran dari Mataram dengan berbagai inkulturasi, serta Tuhan Yang Maha Esa sebagai satu-satunya tuhan yang pantas untuk disembah.

Kata Kunci: ajaran, Tuhan, kepercayaan, dieng, ritual.

\section{A. Pendahuluan}

Dieng menjadi salah satu kiblat bagi penghayat aliran kepercayaan di Nusantara. Ritual-ritual rutin para penghayat kepercayaan dari berbagai tempat di Nusantara seringkali dilakukan. Data dari Dinas Pariwisata dan Kebudayaan, Wonosobo 2005 menyebutkan bahwa di Wonosobo berkembang 58 aliran kepercayaan dan kesemua aliran tersebut menganggap Dieng sebagai kiblat spiritual. Secara mistis, mereka mengaku sebagai penerus leluhur mistis mereka yang bernama Ki Kala Dete yang mendiami Dieng, khususnya sekitar Kawah Sikidang (Dinas Pariwisata dan Kebudayaan Kabupaten Wonosobo, 2005). Ada 
ajaran-ajaran yang cukup menarik, terkait dengan pandangan aliran kepercayaan, Islam, dan Jawa. Selain itu, ada sisi filosofis dalam ajaran mereka sebagai konsep bagi manusia dalam memandang hidup.

Dalam praktik, aliran kepercayaan menjadi salah satu bentuk religi. Perlu diketahui bahwa aliran kepercayaan yang berkembang di Nusantara berisikan pandangan hidup dari berbagai ajaran, yakni animisme dan dinamisme, Hindu, Buddha, dan Islam. Dalam kaitan ini, Dieng menjadi pusat bentuk religi. Konsep ajaran dari aliran kepercayaan mementingkan manusia untuk menuju hidup yang menghayati pesan-pesan ketuhanan. Namun, secara keseluruhan, konsep ajaran mereka lebih dekat dengan Islam dalam dialektika dengan budaya lokal sehingga muncul simbol dan ritual yang unik.

Hubungan aliran kepercayaan dan Islam menjadi sangat dekat dengan metode pengajaran yang dilakukan oleh Sunan Kalijaga, dan pengaruh kuat dari kerajaan Mataram Baru melalui kitab-kitab yang ditulis oleh para rajanya. Bentuk ajaran itu pun menjadi humanis dengan nilai-nilai lokal yang tetap hidup, dan ekosistem yang terjaga. Ada keyakinan bahwa dalam hidup ini harus senantiasa menjaga dunia tempat manusia tinggal dan menyakini keberadaan tuhan sebagai pencipta.

Di dalam suatu bentuk religi akan terdapat konsep teologi atau konsep ketuhanan. Artikel ini membahas konsep teologis aliran kepercayaan di Dieng, yang dalam hal ini lebih dekat dengan ajaran Islam, yakni terkait dengan konsep alam gaib dan asal-usul manusia yang diajarkan pada pengikut dan anak cucu, dan bentuk-bentuk ritual yang menjadi ajaran dan cara untuk mendekatkan diri kepada Tuhan.

\section{B. Tafsir KebudayaAn}

Geertz (1960: 56) memandang tatanan kemasyarakatan dapat diinterpretasi melalui pola kehidupan yang berkembang di dalamnya. Bentuk ritual dan keagamaan merepresentasikan pandangan intelektual masyarakat. Ada keyakinan dan dialektika yang dapat dipelajari sebagai corak kehidupan sebagai sistem gagasan dan sistem tindakan. Dari sekian fenomena budaya yang terkait dengan fenomena sosial, ritual dalam keyakinan memiliki posisi yang sangat penting dalam kehidupan manusia di masyarakat. Hal senada juga diungkapkan oleh Lévi-Strauss (2005: 79) yang memandang "sistem tingkah laku manusia merupakan proyeksi struktur sosial budaya, yang terkait dengan jiwa".

Kebudayaan yang ada di masyarakat perlu untuk diteliti dan dipahami untuk menuju pada kategorisasi dan pola yang ada (Geertz, 1960: 56). Tafsir kebudayaan yang digagas oleh Clifford Geertz mengarahkan unt uk masuk ke 
lapangan. Penelitian lapangan yang bersifat kualitatif dengan melihat dan bergulat langsung di daerah Dieng. Peneliti membekali diri dengan teori-teori yang berkaitan dengan lingkup kawasan Dieng sebagai pusat aliran kepercayaan. Tafsir kebudayaan digunakan sebagai dasar, bukan untuk membingkai aliran kepercayaan di Dieng yang diamati, namun sebagai bekal untuk mempertajam pengamatan, dan wawancara kepada para penganut aliran kepercayaan di Dieng. Pola ajaran mereka banyak mengadopsi pandangan Islam. Pendekatan dari tafsir kebudayaan berusaha mencari pemahaman makna dari ekspresi kebudayaan, daripada sekadar mencari hubungan sebab-akibat aliran kepercayaan di Dieng.

\section{Sekilas tentang Tunggul Sabda}

Aliran kepercayaan di Dieng merupakan aliran yang memiliki kaitan dengan perkembangan aliran kepercayaan di Indonesia. Dari segi ajaran, aliran kepercayaan di Dieng condong kepada ajaran sinkretisme yang memadukan antara agama Islam dan kepercayaan lokal. Salah satu aliran kepercayaan yang ada di Dieng adalah Tunggul Sabda Jati Daya Amungraga yang merupakan ajaran budaya tertua, berasal dari ajaran Semar. Secara leksikal, Tunggul Sabda Jati Daya Amungraga adalah 'tunggul' artinya tinggi, 'sabda' artinya perkataan, 'jati' artinya sejati, 'daya' artinya kekuatan, dan 'amungraga' artinya menjaga tubuh. Secara keseluruhan, Tunggul Sabda Jati Daya Amungraga diartikan sebagai upaya menjaga atau melestarikan budaya leluhur yang berasal dari ajaran Ki Semar.

Secara umum, masyarakat Dieng memeluk agama Islam, tetapi ada beberapa orang yang menganut paham kepercayaan yang dianggap sebagai hasil budaya nenek moyang. Kepercayaan tersebut merupakan perpaduan unsur Islam, Hindu-Buddha dan Animisme. Adanya unsur Islam dalam ajaran dapat terlihat dalam cara mereka percaya adanya surga dan neraka, unsur HinduBuddha di mana mereka percaya adanya Dewa-dewa yang tinggal di gununggunung di Dataran Tinggi Dieng, dan animisme yang mempercayai adanya rohroh penunggu gua-gua yang ada di wilayah Dieng.

\section{Konsep tentang Hidup dan Alam Gaib}

Ajaran ini mengajarkan agar manusia dalam meminta petunjuk kepada Tuhan harus melalui leluhur. Sejatinya, para leluhur masih hidup di alam pangrantunan, yaitu alam gaib sebagai alam antara sebelum manusia ke surga. Menurut narasumber bernama Rusmanto, sebelum kiamat, manusia akan mati dan tinggal di alam yang disebut alam pangrantunan, yaitu alam antara sebagai 
tempat manusia mengalami ujian atau siksa sampai datangnya kiamat, maka manusia dapat hidup kembali atau ber-inkarnasi. Mereka percaya bahwa hidup itu mengalami sembilan kali siklus atau tingkatan di alam pangrantunan, kemudian hidup kembali di dunia untuk memperbaiki kehidupan sebelumnya. Apabila ternyata selama sembilan kali selalu melakukan perbuatan jahat, maka nanti akan dimasukan ke neraka.

Menurut keyakinan, untuk berkomunikasi dengan Tuhan harus dilakukan dengan jiwa yang bersih, yakni semedi (bertapa). Tuhan, menurut mereka adalah Gusti Allah cepak tanpa sinenggolan, ora arah ora enggon, ora papan ora jaman, adoh tanpo wangenan (Tuhan itu dekat tanpa terjamah, tidak berarah tidak menetap, tidak bertempat tidak terikat waktu, jauh tidak berbatas). Artinya, bahwa di manapun manusia berada, di situlah Tuhan juga ada.

Artinya: "Katakanlah: "Aku berlindung kepada Tuhan (yang memelihara dan menguasai) manusia. Raja manusia. Sembahan manusia. Dari kejahatan (bisikan) syaitan yang biasa bersembunyi. Yang membisikkan (kejahatan) ke dalam dada manusia, dari (golongan) jin dan manusia. Dari (golongan) jin dan manusia"(Q.S.114: 1-6).

Dari ayat tersebut, dipahami bahwa ada keyakinan mengenai dimensi manusia dengan alam gaib, yakni dunia jin. Namun demikian, puncak kepercayaan tertinggi tetap kepada Allah sebagai yang menguasai alam semesta.

Dalam keyakinan penganut kepercayaan Kaki Tunggul Sabda Jati Daya Amungraga bahwa gua-gua di Dieng hanya sebatas sarana atau meditasi menyembah Tuhan sang Pencipta. Hal ini oleh mereka dianalogikan sebagaimana yang dilakukan oleh orang Islam saat shalat yang semuanya menghadap ke Kiblat, yaitu sebuah bangunan Kabah yang di dalamnya terdapat batu Hajar Aswat. Orang Islam salat menghadap Kakbah bukan berarti menyembah Kakbah atau batu Hajar Aswad melainkan tetap kepada Tuhan Allah SWT.

Hakikat dalam menyembah Tuhan itu sendiri sejalan dengan Q.S.2:255, yang artinya sebagai berikut:

Allah, tidak ada Tuhan (yang berhak disembah) melainkan dia yang hidup kekal lagi terus-menerus mengurus (makhluk-Nya); tidak mengantuk dan tidak tidur. Kepunyaan-Nya apa yang di langit dan di bumi. Tiada yang dapat memberi syafaat di sisi Allah tanpa izin-Nya? Allah mengetahui apa-apa yang di hadapan mereka dan di belakang mereka, dan mereka tidak mengetahui apa-apa dari ilmu Allah melainkan apa yang dikehendaki-Nya. Kursi Allah meliputi langit dan bumi. dan Allah tidak merasa berat memelihara keduanya, dan Allah Maha Tinggi lagi Maha besar. 
Dari ayat tersebut, dipahami bahwa Allah "yang berhak disembah". Segala yang ada di dunia ini, yang tampak dan dapat didengar oleh manusia merupakan "kepunyaan-Nya." Dengan mendasarkan bahwa yang ada di dunia ini merupakan kepunyaan Allah, maka keberlangsungan hidup perlu untuk dijalankan dengan harmonis. Begitu juga yang ada dalam konsep ajaran orang Jawa untuk menghargai persaudaraan karena semuanya adalah ciptaan Allah.

Orang Jawa harus mengikuti aturan leluhur, seperti menghormati saudara dirinya sendiri saat lahir yang disebut sedulur papat terdiri at as dua kekuatan jahat yaitu aluamah dan amarah dan dua kekuatan baik yaitu șüfiyah dan muțainah (representasi dari ajaran Islam) dengan melakukan puasa dan memberikan sesaji berupa bubur lima warna, yaitu hitam terbuat dari beras hitam, putih dari beras putih, merah dari beras merah, kuning dari beras putih yang diberi warna dari kunir, dan hijau dari beras yang diberi warna hijau dari dedaunan, misal pandan. Hijau diasumsikan sebagai bentuk fisik tubuh sebagai lambang kesuburan. Kemudian juga ditambah dengan kembang telon yang mengandung makna bahwa orang hidup mempunyai tiga kebutuhan yaitu sandang, pangan, dan papan.

Kembang Telon terdiri atas mawar merah, mawar putih, dan kenanga. Makna mawar merah adalah harta, sedangkan mawar putih adalah niat at au cara yang bersih, dan kenanga adalah agar dikenang. Artinya, kembang telon adalah manusia hidup dalam memenuhi kebutuhan hidupnya yaitu sandang, pangan dan papan harus sesuai dengan nilai-nilai luhur dan cara yang halal agar selalu dikenang kebaikannya.

\section{E. Perkembangan Aliran Kepercayaan di Dieng}

Aliran kepercayaan di Gunung Dieng sekarang sudah mulai berkurang pengikutnya. Menurut Pak Rusmanto, aliran kepercayaan di Gunung Dieng sekitar sepuluh orang saja yang masih rutin melakukan ritual. Sebenarnya, aliran kepercayaan masih dijalankan oleh orang-orang yang terkategori tua, namun mereka enggan mengakui disebut menganut aliran kepercayaan. Dalam kronologis waktu, eksistensi aliran kepercayaan mulai memudar semenjak tahun 1990-an ketika terbukanya pengetahuan masyarakat dan mulai berdatangan pengaruh-pengaruh dari luar. Kebanyakan masyarakat di Gunung Dieng sudah beralih pada ajaran Islam secara murni.

Aliran kepercayaan di Gunung Dieng dipimpin oleh Pak Rusmanto dengan aliran yang dianut adalah panggayuh budi luhur. Ajaran ini disebut sebagai ajaran yang melestarikan warisan leluhur, menjaga alam semesta, dan berbuat baik kepada sesama. Maskipun, di kawasan Dieng sendiri jumlah anggota hanya 
berjumlah sepuluh orang, namun Pak Rusmanto mengakui sebenarnya punya murid yang banyak di tempat-tempat jauh. Mereka akan berkumpul pada bulan Sura (Muharam) untuk melakukan ritual bersama. Ritual dipimpin oleh Pak Rusmanto. Mereka biasanya datang pada malam hari untuk melakukan tirakat (tidak tidur) bersama, yang kemudian pagi menjalankan semadi ke beberapa tempat, seperti candi Bima, Kawah Sileri, dan beberapa danau yang dianggap menjadi tempat bersemayam bagi leluhur.

Ibadah yang dijalankan oleh aliran kepercayaan di Gunung Dieng hanya dijalankan sekali dalam sehari, yakni dilakukan pada tengah malam. Ibadah itu dilakukan dengan hening untuk menjalin pertemuan dengan Allah Yang Esa sebagai tuhan. Ibadah ini dijalankan kalau mampu dan punya waktu. Namun, dalam praktik, ada ibadah-ibadah lain yang dilakukan, seperti ritual di gua, candi, bukit, dan telaga. Ritual dilakukan dengan semadi, dengan ada kembang setaman, dupa dan wewangian, serta baju berwarna hitam ataupun pakaian Jawa. ${ }^{1}$ Fungsi dari ritual semadi itu sendiri untuk berbuat baik kepada leluhur dan menjalin keakraban dengannya. Selain itu, juga ada ibadah-ibadah lain untuk mencapai surga, yakni dengan berbuat baik kepada sesama manusia dan kepada alam semesta. Perbuatan baik itu dilakukan dengan adanya rasa untuk saling menjaga, menghormati, serta tolong-menolong dengan ikhlas. ${ }^{2}$

Dalam menjalankan ritual, Pak Rusmanto biasanya ditemani oleh Kamedi (sebagai muridnya) karena ada beberapa perlengkapan dan peralatan yang cukup berat. Biasanya, ia menuju Gunung Kendil pada hari Senin Wage dan Kamis Wage untuk bersemadi di sana. Gunung Kendil adalah tempat moksa Mbah Kaladete. Setelah itu, beberapa gunung dilalui dan bersemadi di sana untuk mengenang leluhur, di Kawah Gunung Kendil menjadi tujuannya untuk menjalin hubungan dengan leluhur karena asal-usul dari orang Dieng zaman dulu bermula dengan dighodog di kawah tersebut. Pak Rusmanto juga memberi sesaji pada Batu Pakuwaja di Gunung Pakuwaja sebagai cara untuk senantiasa mengingat adanya Tuhan yang memberi petuah untuk senantiasa tabah, sabar, dan kokoh dalam menghadapi cobaan. Batu itu juga menjadi simbol kekokohan Pegunungan Dieng.

Manusia dalam hidup ini mengalami sengsara, duka, dan sakit. Bagian penderitaan itulah yang menjadi konsep untuk bersabar menjalani hidup. Seng-

\footnotetext{
${ }^{1}$ Yang disebut pakaian Jawa adalah Batik. Dalam pakaian itu, biasanya disertai dengan udeng, juga bisa blangkon. Kalau untuk sarung dengan motif kotak-kotak tidak diperkenankan karena hal itu dianggap bukan bagian dari Jawa.

${ }^{2}$ Untuk ajarannya yang lengkap ada dalam buku berjudul Warisan Saka Wong Tuamu Piwulang Sejarah Penggayuh Budi Luhur yang ditulis oleh Rusmanto.
} 
sara, duka, dan sakit menjadi siksaan, tapi manusia disarankan untuk berbuat baik agar dia bisa mencapai surga di kehidupan mendatang. Kalau manusia belum bisa berbuat baik, ia akan diturunkan kembali untuk bisa menebus kesalahan yang pernah dijalani. Namun, kalau manusia begitu jahat dan mati, kadang arwahnya tidak diterima sehingga menghuni pada pohon-pohon, batu, ataupun pada tempat-tempat tertentu. Hanya saja, mereka yang penasaran itu juga leluhur, maka perlu untuk didoakan dan didatangi agar tidak mengganggu, serta agar keseimbangan alam semesta ini terjaga.

Aliran kepercayaan di Gunung Dieng juga percaya pada adanya sosok sakti yang menjaga Gunung Dieng. Sebutlah misalnya ada Kaladete. Mbah Kaladete atau yang lebih popular juga disebut sebagai Tumenggung Kaladete adalah sosok yang sakti mandraguna sehingga tidak mati. Dia hanya moksa. Tidak ada yang tahu makamnya. Orang-orang di Gunung Dieng hanya tahu petilasan $^{3}$ (tempat dari Mbah Kaladete melakukan semadi). Tumenggung Kaladete berasal dari kerajaan Medang Kemulyan yang kalah setelah berperang dengan Majapahit, kemudian membentuk kehidupan di Gunung Dieng. Namun, ada versi lain yang mengatakan bahwa Kaladete itu berasal dari kerajaan Kalingga, semasa kepemimpinan Ratu Sima. Adapun Tumenggung Kaladete itu sendiri ditugaskan untuk membentuk kepemimpinan di daerah Dieng.

Keberadaan dari Tumenggung Kaladete inilah yang membuat beberapa anak tertentu memiliki rambut gimbal. Anak yang berambut gimbal adalah anak yang disayang oleh Tumenggung Kaladete. Ada yang mengatakan bahwa anak berambut gimbal itu karena kurang disayang oleh orangtua sehingga menjadi disayang oleh Tumenggung Kaladete, maka untuk menebusnya harus melakukan serangkaian prosesi ritual. Namun, ada pula yang mengatakan bahwa anak yang berambut gimbal itu karena titipan dari Kanjeng Ratu Kidul sehingga untuk ritual, pada acara puncak, rambut gimbal harus dikembalikan ke air yang mengalir ke Pantai Selatan.

Selain Kaladete, menurut Pak Rusmanto bahwa di Gunung Dieng itu juga ada Eyang Semar. Tidak semua orang memang bisa bertemu dengan Eyang Semar. Hanya orang-orang tertentu saja yang dapat bertemu. Eyang Semar inilah yang menjaga Gunung Dieng, yang apabila marah dapat berakibat pada meletusnya gunung. Keberadaan dari Eyang Semar tidak terlalu terpublikasikan secara umum. Yang benar-benar percaya pada keberadaan Eyang Semar di Gunung Dieng hanyalah orang-orang dari aliran kepercayaan.

\footnotetext{
${ }^{3}$ Petilasan berbeda dengan makam. Petilasan adalah tempat untuk semadi, sedangkan makam adalah tempat untuk membaringkan jasad.
} 
Aliran kepercayaan di Gunung Dieng tidak ada hubungannya dengan agama seperti Islam, Hindu/Buddha, namun beberapa esensi yang mereka lakukan sedikit mengalami persinggungan, terutama dengan Islam yang diajarkan oleh Sunan Kalijaga dan ajaran dari Islam Mataram. Misalnya, dikatakan bahwa Eyang Semar itu penjelmaan dari Bapa Adam, dan mereka mengakui memiliki Tuhan Yang Esa: konsep ini selaras dengan Islam. Namun, beberapa praktik dengan bersemadi di gua, bukit, dan candi sejalan dengan ajaran Hindu/Buddha. Dalam pernyataan, mereka lebih sebagai ajaran tersendiri dengan hati sebagai kitab utama untuk menjalin hubungan dengan Tuhan dan melakukan relasi dengan alam-alam lainnya. Hal ini sejalan dengan Q.S.41:53, seperti berikut ini.

Artinya: "Kami akan memperlihatkan kepada mereka tanda-tanda (kekuasaan) kami di segala wilayah bumi dan pada diri mereka sendiri, hingga jelas bagi mereka bahwa al-Qur'an itu adalah benar. Tiadakah cukup bahwa Sesungguhnya Tuhanmu menjadi saksi atas segala sesuatu?"

Dari ayat tersebut, dipahami bahwa relasi dengan Tuhan dapat dipahami dari sisi manapun, bahkan "pada diri mereka sendiri", yang dapat dicapai melalui hati untuk lebih mendekatkan diri. Dalam dimensi ini, dipahami bahwa Tuhan mengetahui semua tingkah laku dan perbuatan manusia di bumi. Semua itu diwujudkan dalam bentuk ritual.

Ritual menjadi bentuk ekspresi receptive orientation (kepuasan) penganut agama terhadap aktivitas keagamaan yang dilakukan, meskipun diyakini atau tidak, berasal dari konstruksi budaya atau warisan leluhurnya, bahkan hasil kolaborasi agama arḍi dan agama samawi. Essensi ritual kepercayaan lebih untuk mengetahui Tuhannya, yang tidak dapat diungkapkan dengan sesuatu apapun, tetapi dapat dirasakan kehadirannya melalui pengalaman spiritual, baik dengan sengaja maupun tidak. Pengalaman ini merupakan bentuk mistik kepasifan yang sering dilakukan oleh penganut kepercayaan untuk menumbuhkan kesakralan dan kekhidmatan dalam pelaksanaan ritual sesuai dengan keyakinan dan kepercayaannya.

\section{F. Simpulan}

Dari pembahasan yang telah dipaparkan, dapat disimpulkan beberapa hal berikut ini. Pertama, bahwa aliran kepercayaan di Dieng mempercayai adanya hidup dan alam gaib, yang mana manusia berasal dari Bapa Adam dan Hawa, juga percaya adanya alam lain. Kedua, transformasi ajaran mereka menyerap dari ajaran Sunan Kalijaga dan beberapa ajaran dari Mataram, namun praktiknya juga masih terpengaruh oleh Hindu dan Buddha. Ketiga, mereka menyem- 
bah Tuhan Yang Maha Esa, yang dapat diimplementasikan dalam berbagai macam tindakan seperti berbuat baik dengan alam, berbuat baik dengan sesama manusia, dan menjalin hubungan dengan Tuhan dengan hati sebagai poros ritual.

\section{Daftar Pustaka}

Ahmadi, Abu. 1991. Perbandingan Agama. Jakarta: Rineka Cipta.

Ajaran Hastha Brata. 2003. Paranporo HPK. Wonosobo (naskah ketikan tangan).

Arif, Ahmad S. 2006. Penguatan Klaster Pariwisata Dieng. Dieng: Yayasan Kembang Emas.

Bambang Sutejo. 2005. Laporan Tahunan Kegiatan Budaya Kabupaten Wonosobo. Wonosobo: Dinas Pariwisata dan Kebuadayaan.

Barthes, Roland. 2011. Mitologi (Mythologies), diterj. oleh Nurhadi dan Sihabul Millah. Yogyakarta: Kreasi Wacana.

Danandjaja, James. 1986. Folklor Indonesia: Ilmu Gosip, Dongeng, dan lainlain. Jakarta: Grafitipers.

Dhofier, Zamakhsyari. 1994. Tradisi Pesantren: Studi tentang Pandangan Hidup Kyai. Jakarta: LP3ES.

Dinas Pariwisata dan Kebudayaan Kabupaten Wonosobo. 2004. Sejarah Wonosobo.

2004. Profil Pariwisata Kab. Wonosobo 2003. Film VCD. 2005. "Pesona Wisata dan Budaya Wonosobo" Leaflet.

Dinas Pariwisata Propinsi Jawa Tengah. 2005. Draft Final Mapping dan Telaah Potensi Kawasan RIPP Jawa Tengah 2004-2009 (Kawasan Wisata Dieng). Semarang: Diparda Jateng.

Durkheim, Emile. 2003. Sejarah Agama. Jakarta: Jang Arafika.

Ernawati, Diyah Bekti dan Bani Sudardi. 2006. Pemberdayaan Masyarakat

Dieng Melalui Sektor Wisata. Surakarta: Laporan penelitian LPPM.

Geertz, Clifford. 1960. The Religion of Java. Illionis: The Free Press of Glencoe. Ihromi, T.I. 2006. Pokok-pokok Antropologi Budaya. Edisi Kedua belas. Jakarta: Yayasan Obor Indonesia.

Kahmad, Dadang. 2000. Sosiologi Agama. Bandung: Remaja Rosdakarya.

Komunitas Masyarakat Peduli Bangsa Kabupaten Wonosobo, 2005. Strategi

Pengembangan Komunitas Budaya Kabupaten Wonosobo 2006-2010". Wonosobo: Dinas Kebudayaan Wonosobo. 
Loekito, H.D. 2003. Tuntunan Lakune Wong Urip: Kaki Tunggul Sabda Jati Daya Among Rogo. Wonosobo: Himpunan Penganut Kepercayaan (HPK).

Mulyono, Sri. 1978. Apa Siapa Semar. Jakarta: Gramedia.

Poerbatjaraka, R.M.Ng. 1952. Kapustakan Djawi. Jakarta: Djambatan.

Pritchard, Evans. 1984. Theories of Primitive Religions (Teori-teori tentang Agama Primitif). Terjemahan Ludjito. Yogyakarta: PLP2M.

Romdon. 1996. Ajaran Ontologi Aliran Kebatinan. Jakarta: Raja Grafindo Persada.

Saifuddin, Achmad Fedyani. 2006. Antropologi Kontemporer: Suatu Pengantar Kritis Mengenai Paradigma, Edisi Pertama, Cetakan ke-2. Jakarta: Kencana.

Santosa, Edi. 2012. "Candi Dieng Sejarah Deskripsi dan Kronologinya” dalam http://www.pesonadieng.com/2012/04/candi-dieng-sejarah-deskripsidan.html

Subiyantoro, Slamet. 2010. Antropologi Seni Rupa: Teori, Metode \& Contoh Telaah Analisis. Cetakan 1. Surakarta: UNS Press.

Sukatno, Otto. 2004. Dieng Poros Dunia. Yogyakata: IRCISOD.

Wawancara dengan Informan Rusmanto, Juru Kunci kompleks wisata Dieng.

[WK-Wonosobo]. 2011. "Sejarah Dieng”, dalam http://wonosobokemekelen. blogspot.com/2011/01/candi-dieng-wonosobo-provinsi-jawa.html.

Zoetmulder. 1935. Pantheisme en Monisme in de Javaansche Soeloek Literature. Den Haag: KITLV. 